\title{
New transmedia design for traditional film festivals
}

\author{
Keywords \\ Film festivals, Media convergence, Platformization, Curation, Transmedia.
}

The disruptive transformations process in the audiovisual sector were unexpectedly accelerated after the covid-19 pandemic. This caused a rearrangement in the chain of the distribution, exhibition and circulation, thus restructuring the whole design of film festivals, once considered the launching point of this entire industry and strongly based on specific physical locations. Streaming has become the main way in which image and sound content are distributed. Entertainment became multiplatform and interactive, changing the way in which narratives are structured, and these contents are produced and consumed. The convergence of media made porous the boundaries between what are conventionally called video, cinema, theater and performance. The platformization process permanently changed the traditional model of audiovisual distribution, staffing and curation of festivals - which undergo a hybridization operation that allows the potential use of interactive resources and online delivery of movies, plays and performances to audiences all around the globe. To understand the potential of transformations, the study investigates in depth the experience of MixBrasil Festival, largest LGBTQIA+ cultural event in Latin America, created in 1993, showcasing multiple formats and techniques (cinema, theater, music, literature). With digital content being programmed since 2018, in 2020 it expanded its online exhibition to four different digital platforms. The study is carried out concurrently with the monitoring of MixBrasil and other film festivals held in Brazil, considering what strategies are being adopted and how they will stand out as innovative - or just replications of the traditional movie theater model. It also aims to identify processes, paths and perspectives for the sector considering that the old template for launching films used since the 1950's might no longer be applicable to the current state of the industry. Facts and trends that are forcing these events to face a crisis of identity and questioning the viability of a (still) prestigious circuit. Platformization implies the adoption of online functionalities integrated at economic and infrastructure levels which fully affects the organization strategies of festivals. Therefore, a change in the way of thinking the place of film festivals in the industry chain is in progress: as a possible space for capturing data from the public to support future curatorships and permanent actions which would make them more dynamic and relevant. Associated with this process is the notion of attention economy and the reorientation of users as active producers of culture, in the way they can affect the hybrid future of festivals. Metrics recurrently used like engagement, geolocation, retention and abandon rates are necessary to identify obstacles and potentialities that the new scenario presents. The research is raising additional questions about the behavior and expectations of different age groups, the motivations of audiences for attending festivals. It also investigates why although movie theaters are closing, distributors keep restrictions on festival theatrical screenings. This is a unique opportunity to reflect on perspectives for audiovisual festivals in order to capture viewers' attention, reposition their relevance to society, get the (re)cognition of different audiences and forge new experiences. 